J Mol Cell Cardiol. 2014 May ; 0: 47-55. doi:10.1016/j.yjmcc.2014.02.017.

\title{
Cardiac Fibroblast in Development and Wound Healing
}

\author{
Arjun Deb ${ }^{1,2,3,4,5}$ and Eric Ubil ${ }^{6}$
}

${ }^{1}$ Division of Cardiology, Department of Medicine, Cardiovascular Research Laboratory, David Geffen School of Medicine, University of California, Los Angeles

${ }^{2}$ Eli and Edythe Broad Center of Regenerative Medicine and Stem Cell Research, David Geffen School of Medicine, University of California, Los Angeles

3Jonsson Comprehensive Cancer Center, David Geffen School of Medicine, University of California, Los Angeles

${ }^{4}$ Molecular Biology Institute, David Geffen School of Medicine, University of California, Los Angeles

${ }^{5}$ Programs in Molecular Cellular \& Integrative Physiology And Cell \& Developmental Biology, David Geffen School of Medicine, University of California, Los Angeles

${ }^{6}$ Department of Cell Biology and Physiology, University of North Carolina, Chapel Hill

\section{Introduction}

Cardiac fibroblasts are cells of mesenchymal nature that reside within the cardiac interstitium $[1,2]$. They comprise the majority of the cells in the adult rodent and human heart and express proteins that maintain homeostasis of the extracellular matrix (ECM)[3, 4]. The interconnected network of cardiac fibroblasts forms the fibrous skeleton of the heart and serves as a scaffold for supporting all cardiac cell types. Aside from maintenance of the extracellular matrix, cardiac fibroblasts express a rich array of growth factors and cytokines and communicate with adjoining myocytes to facilitate electro-mechanical transduction[1, 5]. The fibroblast also lies at the heart of most cardiac pathologies[6]. Common congenital and adult cardiac pathologies are characterized by a loss of cardiac muscle and as the mammalian heart is unable to robustly regenerate, lost cardiac muscle is replaced by fibrosis. Fibrosis induces adverse changes in cardiac geometry and function that leads to progressive chamber enlargement, hypertrophy of viable myocytes, increasing wall tension and ultimately congestive cardiac failure[7-9]. Despite the enormous pathophysiological importance of fibrosis in cardiac diseases, the cardiac fibroblast remains an ill-defined cell

(C) 2014 Elsevier Ltd. All rights reserved.

Address Correspondence to: Arjun Deb, M.D., 675 Charles E Young Drive S, 3609 A MRL Building, University of California, Los Angeles, Los Angeles, CA 90095, Tel:310-825-9911, Fax: 310-206-5777, adeb@mednet.ucla.edu.

Publisher's Disclaimer: This is a PDF file of an unedited manuscript that has been accepted for publication. As a service to our customers we are providing this early version of the manuscript. The manuscript will undergo copyediting, typesetting, and review of the resulting proof before it is published in its final citable form. Please note that during the production process errors may be discovered which could affect the content, and all legal disclaimers that apply to the journal pertain.

Disclosures

None 
and very few interventions effectively target the cardiac fibroblast and fibrosis[10, 11]. This review summarizes the role of the cardiac fibroblast in cardiac development and repair to emphasize the emerging but central role of this cell in regulating cardiac function in health and disease.

\section{The Cardiac Fibroblast In Development}

\section{Developmental origin of cardiac fibroblasts}

Cardiac fibroblasts are thought to be predominantly derived from the epicardium (Figure 1) [1]. Villous like projections protrude from the venous pole of the developing heart to form the proepicardium $[12,13]$. Cells from the pro-epicardium detach and attach on the beating ventricular surface to form the epicardium[14]. Subsequently epithelial cells of the epicardium undergo epithelial-mesenchymal-transition (EMT) to form mesenchymal cells that invade the developing myocardium[15]. A subset of these mesenchymal cells after EMT acquire migratory properties and invade the developing myo-fascial planes to occupy an interstitial position in between cardiac myocytes to become resident cardiac fibroblasts[16, 17].

Cardiac fibroblasts are observed in the developing murine heart by E12.5 days post fertilization (dpf) and their numbers progressively increase throughout development[3]. Using flow cytometry, Banerjee et al estimated that cardiac fibroblasts comprise approximately $14 \%$ of all murine heart cells at E18.5 dpf. Fibroblast numbers progressively increase in the heart in post natal life comprising $27 \%$ of the total number of cells in the adult murine heart (Table 1)[3]. In the rat heart, cardiac fibroblasts constitute approximately $30 \%$ of the total number of heart cells on the first day of life and by the 15 th day of postnatal life, they comprise approximately $2 / 3$ of the total numbers of cells in the rat heart (Table 2)[3, 4]. In humans, non-myocyte cells comprise approximately $70 \%$ of the total number of cardiac cell types[18, 19]. The higher number of fibroblasts in rat and human hearts may be related to a larger heart size, greater wall tension and consequently a need for greater production of ECM[3].

In contrast to cardiac fibroblasts, valvular fibroblasts are thought to be derived from the endothelium overlying the region of the cardiac cushions (site of atrio-ventricular valve formation)[20-22]. The endothelium overlying the valve leaflets undergoes endothelialmesenchymal-transition (EndMT) to generate cardiac fibroblasts that invade the valvular mesenchyme and contribute to the collagenous structure of the valve (Figure 1).

\section{Signals regulating cardiac fibroblast formation during development}

As cardiac fibroblasts are formed via EMT, signals regulating EMT affect fate specification of epicardial cells to form fibroblasts. EMT during development is tightly regulated and complex to analyze as different molecules exhibit species specific differences in the regulation of EMT. Fibroblast growth factors (FGFs) are thought to promote EMT. Members of the transforming growth factor $\beta$ (TGF $\beta$ ) superfamily inhibit EMT in the developing avian heart to regulate the fraction of epicardial cells adopting a mesenchymal phenotype[23]. Notch signaling promotes EndMT and formation of valvular fibroblasts and disruption of Notch signaling in developing cardiac valves leads to formation of atrophic 
valves[24]. Once the epicardial cells undergo EMT, platelet derived growth factor (PDGF) and TGF $\beta$ are thought to promote differentiation into a myofibroblast or cardiac fibroblast phenotype. Platelet derived growth factor receptor (PDGFRa) in particular, is thought to be required for epicardial derived cells to adopt a cardiac fibroblast fate[25]. In addition to secreted molecules, several transcription factors such as $\mathrm{T}$ box transcription factor 18 (Tbx18), Wilms tumor 1 (Wt-1) and members of the snail family also regulate EMT during development[20]. Disruption of Wt-1 in the epicardium increases Snaill levels that subsequently inhibits EMT and increases expression of epithelial markers[26].

\section{Function of cardiac fibroblast during heart development}

In contrast to the well described functions of the cardiac fibroblast in the adult heart, less is known about the role of the cardiac fibroblast in heart development. The number of cardiac fibroblasts progressively increases from E12.5 dpf and the increasing number of fibroblasts form a fibrous skeleton that likely provides structural support for the growing number of cardiac myocytes. Embryonic cardiac fibroblasts compared to adult cardiac fibroblasts express more growth factors and secrete in greater abundance extracellular matrix proteins such as periostin, fibronectin and tenascin C[27]. In co-culture experiments it was observed that fibronectin and type 3 collagen secreted by the embryonic cardiac fibroblast induced proliferation of embryonic cardiac myocytes via a $\beta 1$ integrin receptor dependent mechanism. These observations suggest that cardiac fibroblasts can regulate cardiomyocyte proliferation during development (Figure 2)[27]. Cardiac fibroblasts express angiogenic cytokines such as vascular endothelial growth factor (VEGF) and FGF. During cardiac development, FGF and VEGF drive mesenchymal cells originating from epicardial EMT to adopt an endothelial lineage[28]. Cardiac fibroblasts also express anti-angiogenic cytokines such as connective tissue growth factor (CTGF)[1]. More rigorous studies are needed to address the role of cardiac fibroblast in the regulation of angiogenesis in the embryonic heart.

\section{The Cardiac Fibroblast In Wound Healing}

\section{Origins of cardiac fibroblasts after cardiac injury}

Fibroblasts in the injured heart are thought to have diverse origins (Figure 1). Resident cardiac fibroblasts at the site of injury proliferate and are thought to be the predominant pool of cardiac fibroblasts contributing to cardiac fibrosis after injury, although rigorous fate mapping studies have not been done to confirm this[1]. Early studies using tritiated thymidine demonstrated a small pool of proliferating perivascular cardiac fibroblasts after cardiac injury[18, 29]. Fibrosis around the perivascular region is observed in the early stages of many cardiac pathologic conditions and pericytes and perivascular cells represent another population of cells contributing to fibrosis in the injured heart (Figure 1)[30, 31].

Bone marrow derived cells also contribute to cardiac fibrosis[32]. Several studies have demonstrated that between 3 and $24 \%$ of myofibroblasts in the injured region are of bone marrow origin[33, 34]. These circulating fibroblast precursors have been termed fibrocytes and express hematopoietic (CD45), monocytic (CD11b) and progenitor markers (CD34). The ability of bone marrow derived cells to contribute to cardiac fibrosis appears to be 
physiologically important as inhibition of fibrocyte recruitment diminished fibrosis and had salutary effects on remodeling[33].

We and others have demonstrated that a subset of epicardial cells are activated after acute cardiac injury. Epicardial derived cells undergo EMT to generate cardiac fibroblasts, thus recapitulating a developmental program of epicardial EMT (Figure 1)[35, 36]. Following EMT, epicardial derived cardiac fibroblasts reside in the subepicardial space, express collagen and contribute to a pro-fibrotic repair response. Inhibition of epicardial EMT decreased the number of epicardial derived cardiac fibroblasts but led to cardiac chamber dilatation and worsening ejection fraction. These observations suggest that epicardial derived cardiac fibroblasts play an important physiological role in the cardiac repair response[35].

Endothelial cells undergo endothelial-mesenchymal transition (EndMT) and have been reported to contribute to $30 \%$ of the cardiac fibroblasts in a murine model of pressure overload injury[37], but the degree to which endothelial cells contribute to fibrosis in the acutely injured heart is less certain. The physiological significance of fibroblast diversity in the injured heart is unclear and whether different subsets of cardiac fibroblasts of diverse origins exert disparate effects to co-ordinate a repair process remains an unanswered question.

\section{Function of the cardiac fibroblast in wound healing}

The cardiac fibroblast plays a central role in wound healing after myocardial injury and affects various aspects of the wound healing response from deposition of extracellular matrix proteins to wound angiogenesis and scar maturation (Figure 2). Following acute myocardial infarction, cardiac fibroblasts in the heart become activated and rapidly proliferate. In rodent hearts, peak cardiac fibroblast numbers are achieved within 7-14 days after permanent ligation of the left anterior descending coronary artery[38] and within 3 days of ischemia-reperfusion injury[39]. Four weeks after ischemia-reperfusion injury, the number of cardiac fibroblasts decreases by $90 \%$ compared to its peak, demonstrating the dynamic nature of the fibroblast population in the region of injury. Activated fibroblasts at the site of injury express contractile proteins such as a-smooth muscle actin (myofibroblasts) and secrete ECM proteins (mainly collagens). This early fibrotic repair response is critical for maintenance of cardiac structural integrity and performance after cardiac injury. Disruption of cardiac fibroblast activation early after injury led to impaired wound healing and worsening cardiac performance[35].

In the later phases of wound healing (days to weeks), collagen fibers at the site of injury undergo cross-linking which increases the tensile strength of the scar[40]. The scar subsequently contracts undergoing a reduction in surface area and myofibroblasts expressing contractile proteins are thought to contribute to scar contraction (Figure 2). Scar contraction and thinning lead to adverse changes in ventricular chamber geometry and compliance. The hemodynamic burden on the remaining viable myocytes is increased, and over time, this leads to the development of congestive heart failure. In this section, we cover the various roles of the cardiac fibroblast in early and late wound healing, describe the molecular 
activation of cardiac fibroblasts after cardiac injury and finally discuss how fibroblasts can be targeted for cardiac regeneration.

\section{Production of extracellular matrix}

Homeostasis of the extracellular matrix has been traditionally considered to be the main function of the cardiac fibroblast in the uninjured heart. The cardiac ECM consists of interstitial collagens (predominantly type1 and type 3), proteoglycans, glycoproteins, cytokines, growth factors and proteases[2]. Cardiac fibroblasts not only synthesize new matrix proteins but also express various metalloproteinases (MMPs) that degrade extracellular matrix. In the healthy heart, synthesis and breakdown of extracellular matrix are tightly regulated, but in pathological states, increased MMP expression and activity can lead to excessive ECM degradation and turnover[2, 41]. For instance, in patients with dilated cardiomyopathy, characterized by progressive heart failure and fibrosis, several MMPs including MMP2 were found to be elevated in the myocardial interstitium and extracts of hearts exhibited higher degree of collagenase and proteolytic activity[42-44]. In pressure overload cardiac hypertrophy in humans, MMP expression in the heart increases with the onset of left ventricular failure. In rodent models of pressure overload cardiac hypertrophy, increased expression of MMPs is associated with transition from compensation to heart failure[45, 46]. These observations suggest that dynamic changes in collagen content and turnover are associated with and perhaps contribute to cardiac pathologic states.

Following acute myocardial infarction fibroblasts not only increase the synthesis of ECM proteins at the site of injury (replacement fibrosis) but also increase ECM protein synthesis remote from the injury [7, 47]. The deposition of fibrous tissue in areas remote from the area of injury has been termed reactive fibrosis[1, 48]. Reactive fibrosis contributes to the pathophysiologic process after acute myocardial injury by altering chamber compliance and increasing the stiffness of the ventricles. In the normal heart $85 \%$ of the collagen is type I, while early after injury the predominant type of collagen synthesized particularly in the injury area is type III[49]. Type III collagen is more susceptible to stretch than type I collagen and enables the infarcted ventricle to be more distensible particularly within the first two weeks. As the scar matures, the ratio changes with more of type I collagen predominating than type III $[49,50]$.

\section{Production of cytokines and growth factors}

Cardiac fibroblasts express a rich array of cytokines and growth factors that affects wound healing via autocrine or paracrine mechanisms[51]. The expression of cytokines is markedly altered in diseased conditions, often contributing to the pathophysiological process. After myocardial infarction, cardiac fibroblasts are the main source of expression of the proinflammatory cytokine IL-1 $\beta[7,52]$. IL-1 $\beta$ enhances fibroblast migration and promotes turnover of the cardiac ECM via inhibition of collagen type 1 and type 3 synthesis and increased secretion of MMPs[2, 53]. Cardiac hypertrophy is usually accompanied by cardiac fibrosis and cardiac fibroblasts express the pro-fibrotic cytokine IL-6 that promotes cardiac fibroblast proliferation and fibrosis[54]. It is thought that mechanical stretching of the cardiac fibroblasts, that potentially occurs secondary to cardiac dilatation or changes in 
hemodynamic burden in the heart, induces expression of pro-fibrotic cytokines, expression of ECM proteins and ECM receptors on cardiac fibroblasts[55].

\section{Role in wound angiogenesis}

Endothelial cell proliferation accompanies fibroblast proliferation early after myocardial injury and neovascularization of the injury region promotes wound healing and cardiac repair, while excessive neovascularization beyond the region of injury can promote hemorrhage[56]. Fibroblasts exist in close association to endothelial cells and are known to express pro-angiogenic cytokines (FGF \& VEGF) as well as anti-angiogenic cytokines (PDGF \& CTGF)[51][57]. Fibroblasts also express Tissue inhibitor of metalloproteinases (TIMPs) and TIMPS are known to inhibit and promote angiogenesis in a context dependent manner[58][59]. It is thus possible that fibroblasts contribute to the regulation of wound angiogenesis via expression of angiogenic and anti-angiogenic molecules and more studies will be needed to delineate the role of fibroblasts in regulating post infarct angiogenesis.

\section{Role in electro-mechanical transduction after injury}

Cardiac fibroblasts have high membrane resistance, that makes them good conductors of electrical signals. They can physically communicate with adjoining cardiac myocytes $e x$ vivo through gap junctional proteins such as connexin 43, although the physiological relevance of such interactions in vivo has not been demonstrated[60,61]. As fibrosis is associated with disruption of the normal arrangement of myocytes and fibroblasts, heterogeneity in conduction can occur around the area of fibrosis and predispose to life threatening re-entry tachycardias. How fibroblast to fibroblast and fibroblast to myocyte communication in the region of scar influence the genesis of arrhythmias is an active field of investigation in arrhythmia biology.

\section{Role in scar maturation and contraction}

As alluded earlier in this review, a subset of cardiac fibroblasts after cardiac injury, acquire new phenotypic characteristics, express a-smooth muscle actin and are known as myofibroblasts[62]. The uninjured heart except the valvular interstitum does not have myofibroblasts[63]. In changing their phenotype to a myofibroblast, cardiac fibroblasts are thought to transition via an intermediate stage called proto-myofibroblast, characterized by expression of early stress fibers such as $\beta$-actin and $\gamma$-actin[40, 64]. The protomyofibroblasts subsequently transition into fully differentiated myofibroblasts in the presence of appropriate signals from the ECM as well as neighboring cells[40]. A fully differentiated myofibroblast expresses a-smooth muscle actin but can be distinguished from a smooth muscle cell by low expression of other smooth muscle proteins such as heavy chain smooth muscle myosin[2].

Myofibroblasts contribute to scar contraction and remodeling[63, 65]. Scar maturation and contraction results in decreased surface area of the scar and leads to a thinner scar with greater tensile strength. Renewal of matrix proteins plays a critical role in persistence of scars in other organs such as the liver [66] and myofibroblasts by continuing to turn over matrix proteins likely perpetuate the persistence of scars in the heart[6, 18]. It is interesting to note that in organs such as the skin that retain the ability to heal wounds without scar 
formation, myofibroblasts undergo apoptosis in the later phases of wound healing [48, 67]. Myofibroblasts have been found to be embedded in mature cardiac scars in humans years after myocardial injury and it is not clear whether the persistence of myofibroblasts in chronic scars months or years after cardiac injury is secondary to these cells being resistant to apoptosis[48].

\section{Signals regulating fibroblast activation}

Modulation of signals mediating early fibroblast activation and late remodeling is an area of intense scientific interest for its obvious therapeutic implications. An exhaustive description of mediators and signaling pathways affecting fibroblast function after injury is beyond the scope of this review but in this section we briefly describe some of the major signaling pathways involved. The region of myocardial necrosis is first infiltrated with polymorphonuclear cells. Over the first 48 hours, neutrophils are replaced by a mononuclear/macrophage infiltrate. Macrophages in the region of injury release proinflammatory cytokines, such as TNFa, IL-1 $\beta$ and IL-6 that play an important role in fibroblast activation and proliferation (Figure 3)[39].

The TGF $\beta / S M A D$ axis is known to promote fibroblast activation and proliferation after cardiac injury (Figure 3)[68]. TGF $\beta$ is markedly up-regulated in the infarcted heart with different isoforms displaying different temporal patterns of expression[69]. TGF $\beta 1$ and TGF $\beta 2$ are induced early while TGF $\beta 3$ shows delayed and persistent upregulation[70]. TGF $\beta$ in the acutely injured heart is expressed by macrophages as well as fibroblasts in the injury area. Although the precise functions of the different isoforms are unclear, downstream mediators of TGF $\beta$ (SMAD 2,3,4) are significantly elevated in the infarct area and inhibition of the TGF $\beta / \mathrm{SMAD}$ axis is associated with decreased fibrosis and amelioration of late infarct remodeling[69, 71].

The renin angiotensin system (RAS) is being increasingly recognized to exert pro-fibrotic effects[10, 72, 73]. Angiotensin II levels are elevated in the heart within days of injury and Angiotensin II is known to enhance cardiac fibroblast proliferation and expression of collagens[74]. The expression of angiotensin receptors is more pronounced in cardiac fibroblasts in the injured heart[75] than on cardiac myocytes and pharmacological inhibition of the angiotensin axis has been shown to ameliorate cardiac fibrosis[76]. Furthermore, Angiotensin II has been shown to act upstream of TGF $\beta$ and at least in part, TGF $\beta$ mediates effects of Angiotensin. Thus a complex interaction of the RAS and TGFB/SMAD axis may affect post infarct remodeling (Figure 3)[75].

Endothelin-1 (ET-1) is a potent vasoconstrictor and secreted predominantly by endothelial cells but endothelin can be expressed by inflammatory cells and fibroblasts[77].

Endothelin-1 is a downstream mediator of TGF $\beta$ and some studies suggest that ET-1 can work with TGF $\beta$ to promote myofibroblast persistence (Figure 3) [77, 78]. Ang II can also exert its effects via ET- 1 and these studies suggest that ET- 1 can work downstream of TGF $\beta$ and Ang II to drive fibroblast activation. Endothelin antagonists are currently approved for the treatment of pulmonary hypertension and future studies will determine their benefit in cardiac fibrosis[79]. 
Signaling systems important for cardiovascular development have also recently been shown to regulate cardiac fibrosis and repair after acute injury. We demonstrated that epicardial cells expressed Wnt 1 after acute ischemic cardiac injury and Wnt 1 expressing epicardial cells, in a $\beta$-catenin dependent manner, underwent EMT to adopt a fibroblast phenotype[35]. A dynamic notch signaling injury response has been shown to activate the epicardium and contribute to epicardial derived cardiac fibroblasts[36]. Thymosin $\beta 4$ promotes epicardial cell migration and differentiation of epicardial progenitors to promote neovascularization[80]. Although currently, there is no specific therapy for the treatment of cardiac fibrosis, the detailed dissection of signaling pathways affecting various aspects of fibroblast activation provide fresh opportunity for targeting the cardiac fibroblast.

\section{Fibroblasts and cardiac regeneration}

More recently, reprogramming techniques have been applied to induce a fibroblast to change fate into a cardiomyocyte (Figure 4). Cardiac fibroblasts isolated from the skin can be transduced with a cocktail of transcription factors to create induced pluripotent stem (iPS) cells. Such iPS cells can be differentiated in-vitro to generate patient specific cardiomyocytes that could be transplanted into a failing or infarcted heart (Figure 4A). More recently, direct reprogramming approaches have been described where the introduction of a specific combination of factors can directly reprogram a cardiac fibroblast to a cardiomyocyte without having the fibroblast transition through a primitive undifferentiated state (Figure 4A). This technique is particularly appealing as introduction of such factors into fibroblasts in the region of scar can potentially change the fate of a fibroblast to a cardiac myocyte and reverse scarring (Figure 4B).

Ieda. et al demonstrated that a combination of transcription factors GATA4, Mef2C and TBX5 (GMT) when introduced into a cardiac fibroblast are sufficient to reprogram a cardiac fibroblast into a cardiomyoycte[81]. Moreover, the groups of Olson and Srivastava demonstrated that such direct reprogramming can also occur in vivo. The cocktail of transcription factors (GMT or GMT and Hand2) administered to mice hearts via retroviruses following myocardial infarction was sufficient to reprogram scar tissue into cardiac muscle cells that appeared to integrate with surrounding myocardium[82, 83]. Wada. et al have more recently demonstrated that the addition of Mesp1 and Myocardin to the GMT cocktail of transcription factors can induce human dermal fibroblasts to adopt a cardiomyogenic like fate[84]. Jayawardena. et al showed that delivery of a combination of microRNAs is sufficient to reprogram fibroblasts into a cardiomyogenic fate[85].

However with all the above reports, the fraction of fibroblasts undergoing successful direct reprogramming in-vivo into cardiac muscle cells remains small. More efficient delivery systems of transgenes or identification of novel factors that greatly increase the efficiency of direct fibroblast-myocyte reprogramming are needed for successful manipulation of large scars. Nevertheless, this method of directly reprogramming scar tissue into cardiomyocytes is undeniably attractive as it has the promise of changing chronic scar tissue into cardiac muscle cells and potentially reverse post infarct remodeling (Figure 4B). 


\section{Future Directions}

There is mounting clinical evidence to suggest that fibrosis is an independent predictor of mortality and sudden death in patients with heart failure. Patients with a similar ejection fraction but having significantly greater cardiac fibrosis have a poorer prognosis[86]. There is no specific treatment for fibrosis and there is a dire need for major biological questions regarding cardiac fibrosis to be answered.

In this concluding section, we discuss some of the major questions that remain unanswered in the field of cardiac fibrosis. First, given the diversity of origin of fibroblasts contributing to cardiac injury, are there specific subsets of fibroblasts that need to be targeted both in the early and late phases of wound healing? Using fate mapping techniques, Kalluri's group recently demonstrated that after kidney injury, approximately 50\% of fibroblasts in the injury area are of interstitial origin where as the remaining pool is derived from the bone marrow, endothelium (via endothelial-mesenchymal-transition) and epithelium (via EMT) [87]. Recent observations made in skin wound healing also suggest that different lineages of fibroblasts contribute to different aspects of wound healing in the skin[88]. Fibroblasts in the lower dermis are responsible for the deposition of extracellular matrix proteins and fibroblasts in the upper dermis are recruited only during re-epithelialization. Such concepts of specification of fibroblasts during wound healing can be tested in the heart after myocardial injury and can potentially identify whether specific subsets of fibroblasts should be targeted. In this regard, rigorous fate mapping studies should also be performed in the developing heart to identify other potential cell sources contributing to the cardiac fibroblast pool. Elucidation of mechanisms that promote cardiac fibroblast proliferation in the developing heart may identify new signaling pathways that regulate fibroblast activation after cardiac injury.

Second, identification of mechanisms perpetuating the persistence of scars long after injury are of paramount importance. In the liver, under certain circumstances, fibrosis is known to regress and regression of hepatic scars is thought to be secondary to inadequate ECM renewal rather than active catabolism and breakdown of collagen. Do scars in the heart persist secondary to continuous turnover of matrix proteins by myofibroblasts? What then are the factors driving myofibroblast turnover of ECM proteins long after cardiac injury?

Finally can cardiac fibrosis be reversed? Advances in direct reprogramming technology have provided proof of concept that fibroblasts in cardiac scar can be directly reprogrammed into cardiomyocytes. In theory, if a large number of myofibroblasts in the scarred region can be coaxed to adopt a cardiac muscle fate, there should be diminution in the amount of fibrosis. Moreover this strategy also generates new cardiac muscle in the region of scar formation and can potentially reverse deleterious ventricular remodeling. However, pockets of newly generated cardiomyocytes that do not integrate with surrounding cardiac muscle can lead to the formation of arrhythmogenic foci. This technology is also currently limited by the poor efficiency of fibroblast to cardiomyocyte reprogramming in-vivo. Optimization of transgene delivery as well as identification of factors that enhance the efficiency of direct reprogramming will be needed prior to translating these observations into clinical practice. Understanding the physiologic basis of fibroblast diversity, mechanisms regulating the 
persistence of scars and manipulation of fibroblast plasticity in a spatiotemporal manner will be key for treating pathologic cardiac fibrosis.

\section{List of abbreviations}

$\begin{array}{ll}\text { CTGF } & \text { Connective tissue growth factor } \\ \text { ECM } & \text { Extracellular matrix } \\ \text { EMT } & \text { Epithelial-mesenchymal-transition } \\ \text { EndMT } & \text { Endothelial-mesenchymal-transition } \\ \text { FGF } & \text { Fibroblast growth factor } \\ \text { IL } & \text { Interleukin } \\ \text { MMP } & \text { Matrix metalloproteinase } \\ \text { TGF } & \text { Transforming growth factor } \\ \text { PDGF } & \text { Platelet derived growth factor } \\ \text { PDGFR } & \text { Platelet derived growth factor receptor } \\ \text { RAS } & \text { Renin-angiotensin system } \\ \text { TIMP } & \text { Tissue inhibitor of metalloproteinase } \\ \text { Wt-1 } & \text { Wilms tumor 1 } \\ \text { Tbx } & \text { T-box transcription factor } \\ \text { Mef } & \text { Myocyte enhancer factor }\end{array}$

\section{Bibliography}

1. Krenning G, Zeisberg EM, Kalluri R. The origin of fibroblasts and mechanism of cardiac fibrosis. J Cell Physiol. 2010; 225:631-637. [PubMed: 20635395]

2. Souders CA, Bowers SL, Baudino TA. Cardiac fibroblast: the renaissance cell. Circ Res. 2009; 105:1164-1176. [PubMed: 19959782]

3. Banerjee I, Fuseler JW, Price RL, Borg TK, Baudino TA. Determination of cell types and numbers during cardiac development in the neonatal and adult rat and mouse. Am J Physiol Heart Circ Physiol. 2007; 293:H1883-H1891. [PubMed: 17604329]

4. Zak R. Development and proliferative capacity of cardiac muscle cells. Circ Res. 1974; 35(suppl II): 17-26. [PubMed: 4276486]

5. Zeisberg EM, Kalluri R. Origins of cardiac fibroblasts. Circ Res. 2010; 107:1304-1312. [PubMed: 21106947]

6. Baudino TA, Carver W, Giles W, Borg TK. Cardiac fibroblasts: friend or foe? Am J Physiol Heart Circ Physiol. 2006; 291:H1015-H1026. [PubMed: 16617141]

7. Cleutjens JP, Verluyten MJ, Smiths JF, Daemen MJ. Collagen remodeling after myocardial infarction in the rat heart. Am J Pathol. 1995; 147:325-338. [PubMed: 7639329]

8. Cohn J. Cardiac remodeling. J Am Coll Cardiol. 2000:14.

9. Cohn JN, Ferrari R, Sharpe N. Cardiac remodeling--concepts and clinical implications: a consensus paper from an international forum on cardiac remodeling. Behalf of an International Forum on Cardiac Remodeling. J Am Coll Cardiol. 2000; 35:569-582. [PubMed: 10716457]

10. Burchfield JS, Xie M, Hill JA. Pathological ventricular remodeling: mechanisms: part-1 of 2. Circulation. 2013; 128:388-400. [PubMed: 23877061] 
11. Xie M, Burchfield JS, Hill JA. Pathological ventricular remodeling: therapies: part 2 of 2. Circulation. 2013; 128:1021-1030. [PubMed: 23979628]

12. Manner J, Perez-Pomares JM, Macias D, Munoz-Chapuli R. The origin, formation and developmental significance of the epicardium: a review. Cells Tissues Organs. 2001; 169:89-103. [PubMed: 11399849]

13. Juan Manuel Gonzalez-Rosa NM. The epicardium: development, differentiation and its role during heart development. Nature Reviews Cardiology. 2009; 6:1-6.

14. Lie-Venema H, van den Akker NMS, Bax NAM, Winter EM, Maas S, Kekarainen T, et al. Origin, Fate, and Function of Epicardium-Derived Cells (EPDCs) in Normal and Abnormal Cardiac Development. The ScientificWorld Journal. 2007; 7:1777-1798.

15. Manner J. Does the subepicardial mesenchyme contribute myocardioblasts to the myocardium of the chick embryo heart? A quail-chick chimera study tracing the fate of the epicardial primordium. Anat Rec. 1999; 255:212-226. [PubMed: 10359522]

16. Perez-Pomares JM, Carmona R, Gonzalez-Iriarte M, Atencia G, Wessels A, Munoz-Chapuli R. Origin of coronary endothelial cells from epicardial mesothelium in avian embryos. Int J Dev Biol. 2002; 46:1005-1013. [PubMed: 12533024]

17. Gittenberger-de Groot AC, Vrancken Peeters MP, Mentink MM, Gourdie RG, Poelmann RE. Epicardium-derived cells contribute a novel population to the myocardial wall and the atrioventricular cushions. Circ Res. 1998; 82:1043-1052. [PubMed: 9622157]

18. Camelliti P, Borg TK, Kohl P. Structural and functional characterisation of cardiac fibroblasts. Cardiovasc Res. 2005; 65:40-51. [PubMed: 15621032]

19. Adler CP, Ringlage WP, Bohm N. [DNA content and cell number in heart and liver of children. Comparable biochemical, cytophotometric and histological investigations (author's transl)]. Pathol Res Pract. 1981; 172:25-41. [PubMed: 7312710]

20. Kovacic JC, Mercader N, Torres M, Boehm M, Fuster V. Epithelial-to-mesenchymal and endothelial-to-mesenchymal transition: from cardiovascular development to disease. Circulation. 2012; 125:1795-1808. [PubMed: 22492947]

21. Eisenberg LM, Markwald RR. Molecular Regulation of Atrioventricular Valvuloseptal Morphogenesis. Circ Res. 1995; 77:1-6. [PubMed: 7788867]

22. Markwald RR, Fitzharris TP, Manasek FJ. Structural development of endocardial cushions. Am J Anat. 1977; 148:85-119. [PubMed: 842477]

23. Morabito CJ, Dettman RW, Kattan J, Collier JM, Bristow J. Positive and negative regulation of epicardial-mesenchymal transformation during avian heart development. Developmental Biology. 2001; 234:204-215. [PubMed: 11356030]

24. Timmerman LA, Grego-Bessa J, Raya A, Bertran E, Perez-Pomares JM, Diez J, et al. Notch promotes epithelial-mesenchymal transition during cardiac development and oncogenic transformation. Genes Dev. 2004; 18:99-115. [PubMed: 14701881]

25. Smith CL, Baek ST, Sung CY, Tallquist MD. Epicardial-derived cell epithelial-to-mesenchymal transition and fate specification require PDGF receptor signaling. Circ Res. 2011; 108:e15-e26. [PubMed: 21512159]

26. Martinez-Estrada OM, Lettice LA, Essafi A, Guadix JA, Slight J, Velecela V, et al. Wt1 is required for cardiovascular progenitor cell formation through transcriptional control of Snail and Ecadherin. Nat Genet. 2010; 42:89-93. [PubMed: 20023660]

27. Ieda M, Tsuchihashi T, Ivey KN, Ross RS, Hong TT, Shaw RM, et al. Cardiac fibroblasts regulate myocardial proliferation through beta1 integrin signaling. Dev Cell. 2009; 16:233-244. [PubMed: 19217425]

28. Tomanek RJ, Zheng W, Peters KG, Lin P, Holifield JS, Suvarna PR. Multiple growth factors regulate coronary embryonic vasculogenesis. Dev Dyn. 2001; 221:265-273. [PubMed: 11458387]

29. Bishop JE, Laurent GJ. Collagen turnover and its regulation in the normal and hypertrophying heart. Eur Heart J. 1995; 16(Suppl C):38-44. [PubMed: 7556271]

30. Alonso E, Gomez-Santos L, Madrid JF, Saez F. The expression of a novel cxcr4 gene in Xenopus embryo. Histol Histopathol. 2009; 24:1097-1103. [PubMed: 19609856]

31. Vracko R, Thorning D. Contractile cells in rat myocardial scar tissue. Lab Invest. 1991; 65:214227. [PubMed: 1881123] 
32. Bellini A, Mattoli S. The role of the fibrocyte, a bone marrow-derived mesenchymal progenitor, in reactive and reparative fibroses. Lab Invest. 2007; 87:858-870. [PubMed: 17607298]

33. Haudek SB, Xia Y, Huebener P, Lee JM, Carlson S, Crawford JR, et al. Bone marrow-derived fibroblast precursors mediate ischemic cardiomyopathy in mice. Proc Natl Acad Sci U S A. 2006; 103:18284-18289. [PubMed: 17114286]

34. van Amerongen MJ, Bou-Gharios G, Popa E, van Ark J, Petersen AH, van Dam GM, et al. Bone marrow-derived myofibroblasts contribute functionally to scar formation after myocardial infarction. J Pathol. 2008; 214:377-386. [PubMed: 18095257]

35. Duan J, Gherghe C, Liu D, Hamlett E, Srikantha L, Rodgers L, et al. Wnt1/betacatenin injury response activates the epicardium and cardiac fibroblasts to promote cardiac repair. EMBO J. 2012; 31:429-442. [PubMed: 22085926]

36. Russell JL, Goetsch SC, Gaiano NR, Hill JA, Olson EN, Schneider JW. A dynamic notch injury response activates epicardium and contributes to fibrosis repair. Circ Res. 2011; 108:51-59. [PubMed: 21106942]

37. Zeisberg EM, Tarnavski O, Zeisberg M, Dorfman AL, McMullen JR, Gustafsson E, et al. Endothelial-to-mesenchymal transition contributes to cardiac fibrosis. Nat Med. 2007; 13:952961. [PubMed: 17660828]

38. Holmes JW, Borg TK, Covell JW. Structure and mechanics of healing myocardial infarcts. Annu Rev Biomed Eng. 2005; 7:223-253. [PubMed: 16004571]

39. Christia P, Bujak M, Gonzalez-Quesada C, Chen W, Dobaczewski M, Reddy A, et al. Systematic characterization of myocardial inflammation, repair, and remodeling in a mouse model of reperfused myocardial infarction. J Histochem Cytochem. 2013; 61:555-570. [PubMed: 23714783]

40. van den Borne SW, Diez J, Blankesteijn WM, Verjans J, Hofstra L, Narula J. Myocardial remodeling after infarction: the role of myofibroblasts. Nat Rev Cardiol. 2010; 7:30-37. [PubMed: 19949426]

41. Spinale F. Myocardial Matrix Remodeling and the Matrix Metalloproteinases: Influence on Cardiac Form and Function. Physiological Reviews. 2007; 87:1285-1342. [PubMed: 17928585]

42. Spinale FG, Coker ML, Krombach SR, Mukherjee R, Hallak H, Houck WV, et al. Matrix metalloproteinase inhibition during the development of congestive heart failure : effects on left ventricular dimensions and function. Circ Res. 1999; 85:364-376. [PubMed: 10455065]

43. Sivakumar P, Gupta S, Sarkar S, Sen S. Upregulation of lysyl oxidase and MMPs during cardiac remodeling in human dilated cardiomyopathy. Mol Cell Biochem. 2008; 307:159-167. [PubMed: 17849172]

44. Gunja-Smith Z, Morales AR, Romanelli R, Woessner JF Jr. Remodeling of human myocardial collagen in idiopathic dilated cardiomyopathy. Role of metalloproteinases and pyridinoline crosslinks. Am J Pathol. 1996; 148:1639-1648. [PubMed: 8623931]

45. Polyakova V, Hein S, Kostin S, Ziegelhoeffer T, Schaper J. Matrix metalloproteinases and their tissue inhibitors in pressure-overloaded human myocardium during heart failure progression. J Am Coll Cardiol. 2004; 44:1609-1618. [PubMed: 15489093]

46. Kuster GM, Kotlyar E, Rude MK, Siwik DA, Liao R, Colucci WS, et al. Mineralocorticoid receptor inhibition ameliorates the transition to myocardial failure and decreases oxidative stress and inflammation in mice with chronic pressure overload. Circulation. 2005; 111:420-427. [PubMed: 15687129]

47. Sun Y, Weber KT. Infarct scar: a dynamic tissue. Cardiovasc Res. 2000; 46:250-256. [PubMed: 10773228]

48. Turner NA, Porter KE. Function and fate of myofibroblasts after myocardial infarction. Fibrogenesis Tissue Repair. 2013; 6:5. [PubMed: 23448358]

49. Jugdutt BI. Ventricular remodeling after infarction and the extracellular collagen matrix: when is enough enough? Circulation. 2003; 108:1395-1403. [PubMed: 12975244]

50. Jugdutt BI. Left ventricular rupture threshold during the healing phase after myocardial infarction in the dog. Can J Physiol Pharmacol. 1987; 65:307-316. [PubMed: 3580953] 
51. Zhao L, Eghbali-Webb M. Release of pro- and anti-angiogenic factors by human cardiac fibroblasts: effects on DNA synthesis and protection under hypoxia in human endothelial cells. Biochim Biophys Acta. 2001; 1538:273-282. [PubMed: 11336798]

52. Long CS. The role of interleukin-1 in the failing heart. Heart Fail Rev. 2001; 6:81-94. [PubMed: 11309527]

53. Mitchell MD, Laird RE, Brown RD, Long CS. IL-1beta stimulates rat cardiac fibroblast migration via MAP kinase pathways. Am J Physiol Heart Circ Physiol. 2007; 292:H1139-H1147. [PubMed: 17085539]

54. Banerjee I, Fuseler JW, Intwala AR, Baudino TA. IL-6 loss causes ventricular dysfunction, fibrosis, reduced capillary density, and dramatically alters the cell populations of the developing and adult heart. Am J Physiol Heart Circ Physiol. 2009; 296:H1694-H1704. [PubMed: 19234091]

55. van Wamel AJ, Ruwhof C, van der Valk-Kokshoom LE, Schrier PI, van der Laarse A. The role of angiotensin II, endothelin-1 and transforming growth factor-beta as autocrine/paracrine mediators of stretch-induced cardiomyocyte hypertrophy. Mol Cell Biochem. 2001; 218:113-124. [PubMed: 11330825]

56. Hsieh PC, Davis ME, Lisowski LK, Lee RT. Endothelial-cardiomyocyte interactions in cardiac development and repair. Annu Rev Physiol. 2006; 68:51-66. [PubMed: 16460266]

57. Villaschi S, Nicosia RF. Paracrine interactions between fibroblasts and endothelial cells in a serum-free coculture model. Modulation of angiogenesis and collagen gel contraction. Lab Invest. 1994; 71:291-299. [PubMed: 7521446]

58. Ikenaka Y, Yoshiji H, Kuriyama S, Yoshii J, Noguchi R, Tsujinoue H, et al. Tissue inhibitor of metalloproteinases-1 (TIMP-1) inhibits tumor growth and angiogenesis in the TIMP-1 transgenic mouse model. Int J Cancer. 2003; 105:340-346. [PubMed: 12704667]

59. Saunders WB, Bohnsack BL, Faske JB, Anthis NJ, Bayless KJ, Hirschi KK, et al. Coregulation of vascular tube stabilization by endothelial cell TIMP-2 and pericyte TIMP-3. J Cell Biol. 2006; 175:179-191. [PubMed: 17030988]

60. Angst BD, Khan LU, Severs NJ, Whitely K, Rothery S, Thompson RP, et al. Dissociated spatial patterning of gap junctions and cell adhesion junctions during postnatal differentiation of ventricular myocardium. Circ Res. 1997; 80:88-94. [PubMed: 8978327]

61. Baudino TA, McFadden A, Fix C, Hastings J, Price R, Borg TK. Cell patterning: interaction of cardiac myocytes and fibroblasts in three-dimensional culture. Microsc Microanal. 2008; 14:117125. [PubMed: 18312716]

62. Gabbiani G, Ryan GB, Majne G. Presence of modified fibroblasts in granulation tissue and their possible role in wound contraction. Experientia. 1971; 27:549-550. [PubMed: 5132594]

63. Tomasek JJ, Gabbiani G, Hinz B, Chaponnier C, Brown RA. Myofibroblasts and mechanoregulation of connective tissue remodelling. Nat Rev Mol Cell Biol. 2002; 3:349-363. [PubMed: 11988769]

64. Hinz B, Gabbiani G. Mechanisms of force generation and transmission by myofibroblasts. Curr Opin Biotechnol. 2003; 14:538-546. [PubMed: 14580586]

65. Calderone A, Bel-Hadj S, Drapeau J, El-Helou V, Gosselin H, Clement R, et al. Scar myofibroblasts of the infarcted rat heart express natriuretic peptides. J Cell Physiol. 2006; 207:165-173. [PubMed: 16270351]

66. Kisseleva T, Brenner DA. Anti-fibrogenic strategies and the regression of fibrosis. Best Pract Res Clin Gastroenterol. 2011; 25:305-317. [PubMed: 21497747]

67. Desmouliere A, Redard M, Darby I, Gabbiani G. Apoptosis mediates the decrease in cellularity during the transition between granulation tissue and scar. Am J Pathol. 1995; 146:56-66. [PubMed: 7856739]

68. Nian M, Lee P, Khaper N, Liu P. Inflammatory cytokines and postmyocardial infarction remodeling. Circ Res. 2004; 94:1543-1553. [PubMed: 15217919]

69. Bujak M, Frangogiannis N. The role of TGF- $\beta$ signaling in myocardial infarction and cardiac remodeling. Cardiovascular Research. 2007; 74:184-195. [PubMed: 17109837]

70. Deten A, Holzl A, Leicht M, Barth W, Zimmer HG. Changes in extracellular matrix and in transforming growth factor beta isoforms after coronary artery ligation in rats. J Mol Cell Cardiol. 2001; 33:1191-1207. [PubMed: 11444923] 
71. Bujak M, Ren G, Kweon H, Dobaczewski M, Reddy A, Taffet G, et al. Essential Role of Smad3 in Infarct Healing and in the Pathogenesis of Cardiac Remodeling. Circulation. 2007; 116:21272138. [PubMed: 17967775]

72. Pfeffer JM, Fischer TA, Pfeffer MA. Angiotensin-converting enzyme inhibition and ventricular remodeling after myocardial infarction. Annu Rev Physiol. 1995; 57:805-826. [PubMed: 7778884]

73. Yang F, Chung AC, Huang XR, Lan HY. Angiotensin II induces connective tissue growth factor and collagen I expression via transforming growth factor-beta-dependent and -independent Smad pathways: the role of Smad3. Hypertension. 2009; 54:877-884. [PubMed: 19667256]

74. Rosenkranz S. TGF-beta1 and angiotensin networking in cardiac remodeling. Cardiovasc Res. 2004; 63:423-432. [PubMed: 15276467]

75. Gray MO, Long CS, Kalinyak JE, Li HT, Karliner JS. Angiotensin II stimulates cardiac myocyte hypertrophy via paracrine release of TGF-beta 1 and endothelin-1 from fibroblasts. Cardiovasc Res. 1998; 40:352-363. [PubMed: 9893729]

76. Diez J, Querejeta R, Lopez B, Gonzalez A, Larman M, Martinez Ubago JL. Losartan-dependent regression of myocardial fibrosis is associated with reduction of left ventricular chamber stiffness in hypertensive patients. Circulation. 2002; 105:2512-2517. [PubMed: 12034658]

77. Shi-Wen X, Rodriguez-Pascual F, Lamas S, Holmes A, Howat S, Pearson JD, et al. Constitutive ALK5-independent c-Jun N-terminal kinase activation contributes to endothelin-1 overexpression in pulmonary fibrosis: evidence of an autocrine endothelin loop operating through the endothelin A and B receptors. Mol Cell Biol. 2006; 26:5518-5527. [PubMed: 16809784]

78. Shi-wen X, Kennedy L, Renzoni EA, Bou-Gharios G, du Bois RM, Black CM, et al. Endothelin is a downstream mediator of profibrotic responses to transforming growth factor beta in human lung fibroblasts. Arthritis Rheum. 2007; 56:4189-4194. [PubMed: 18050250]

79. Leask A. Potential therapeutic targets for cardiac fibrosis: TGFbeta, angiotensin, endothelin, CCN2, and PDGF, partners in fibroblast activation. Circ Res. 2010; 106:1675-1680. [PubMed: 20538689]

80. Smart N, Risebro CA, Melville AA, Moses K, Schwartz RJ, Chien KR, et al. Thymosin beta4 induces adult epicardial progenitor mobilization and neovascularization. Nature. 2007; 445:177182. [PubMed: 17108969]

81. Ieda M, Fu JD, Delgado-Olguin P, Vedantham V, Hayashi Y, Bruneau BG, et al. Direct reprogramming of fibroblasts into functional cardiomyocytes by defined factors. Cell. 2010; 142:375-386. [PubMed: 20691899]

82. Qian L, Huang Y, Spencer CI, Foley A, Vedantham V, Liu L, et al. In vivo reprogramming of murine cardiac fibroblasts into induced cardiomyocytes. Nature. 2012; 485:593-598. [PubMed: 22522929]

83. Song K, Nam YJ, Luo X, Qi X, Tan W, Huang GN, et al. Heart repair by reprogramming nonmyocytes with cardiac transcription factors. Nature. 2012; 485:599-604. [PubMed: 22660318]

84. Wada R, Muraoka N, Inagawa K, Yamakawa H, Miyamoto K, Sadahiro T, et al. Induction of human cardiomyocyte-like cells from fibroblasts by defined factors. Proc Natl Acad Sci U S A. 2013; 110:12667-12672. [PubMed: 23861494]

85. Jayawardena TM, Egemnazarov B, Finch EA, Zhang L, Payne JA, Pandya K, et al. MicroRNAmediated in vitro and in vivo direct reprogramming of cardiac fibroblasts to cardiomyocytes. Circ Res. 2012; 110:1465-1473. [PubMed: 22539765]

86. Gulati A, Jabbour A, Ismail TF, Guha K, Khwaja J, Raza S, et al. Association of fibrosis with mortality and sudden cardiac death in patients with nonischemic dilated cardiomyopathy. Jama. 2013; 309:896-908. [PubMed: 23462786]

87. LeBleu VS, Taduri G, O'Connell J, Teng Y, Cooke VG, Woda C, et al. Origin and function of myofibroblasts in kidney fibrosis. Nat Med. 2013; 19:1047-1053. [PubMed: 23817022]

88. Driskell RR, Lichtenberger BM, Hoste E, Kretzschmar K, Simons BD, Charalambous M, et al. Distinct fibroblast lineages determine dermal architecture in skin development and repair. Nature. 2013; 504:277-281. [PubMed: 24336287] 


\section{HIGHLIGHTS}

- Cardiac fibroblasts are the most abundant cardiac cell type

- Fibroblasts regulate cardiomyocyte proliferation during heart development

- Fibroblast activation is a critical early repair response after cardiac injury

- Persistence of fibroblasts in injury area leads to chronic scar and remodeling

- Reprogramming fibroblasts to myocytes can be a new strategy for treating cardiac scar 


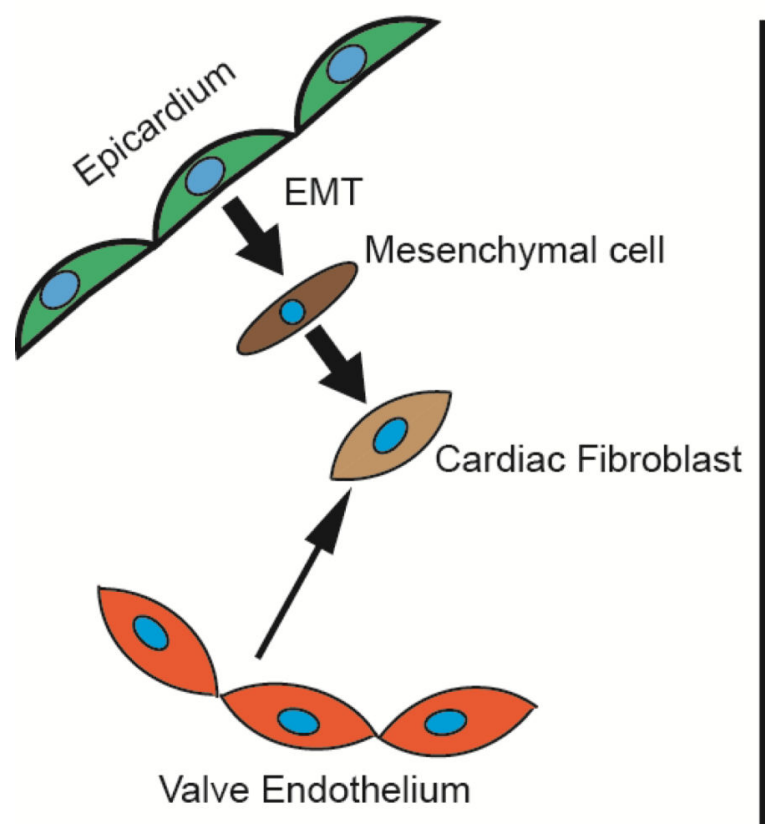

Valve Endothelium

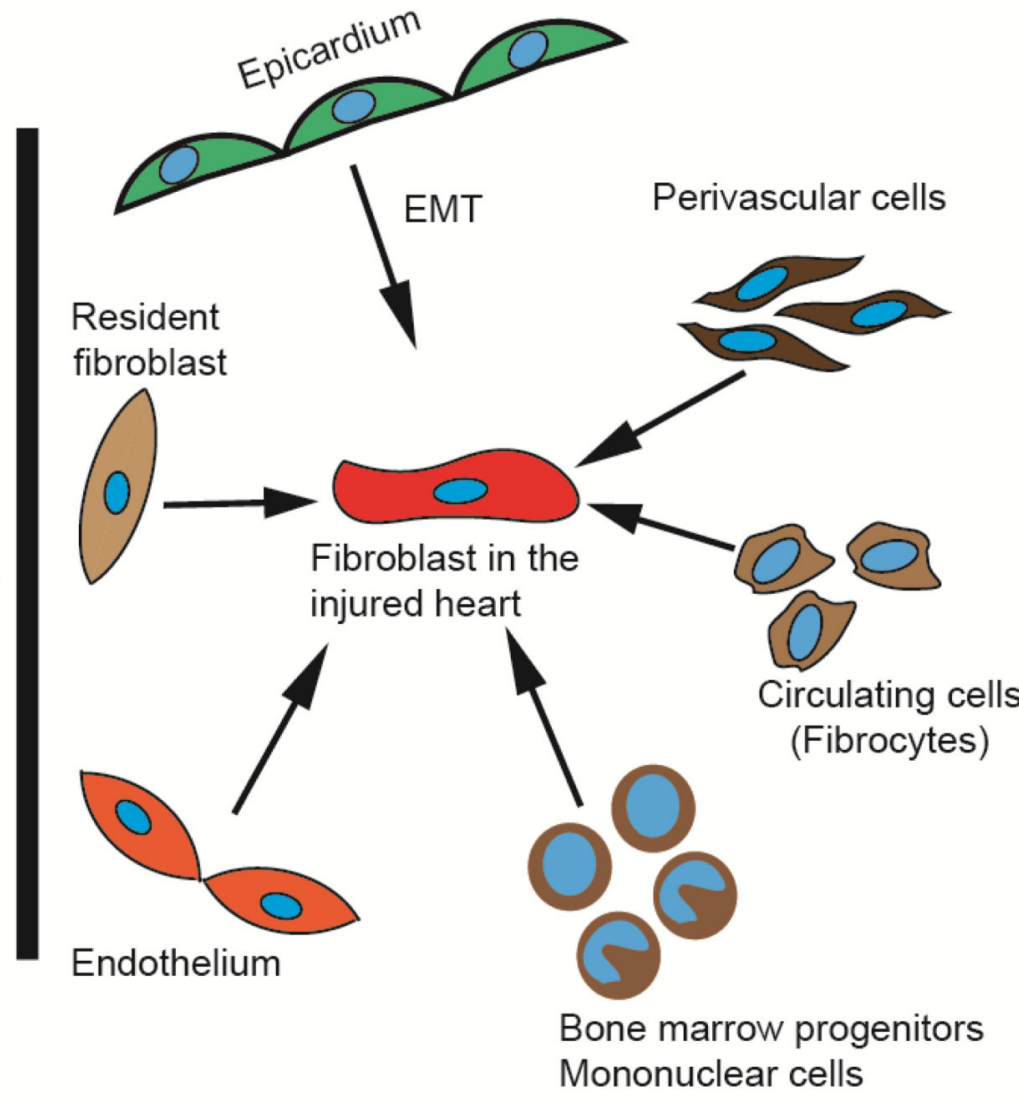

Acute ischemic injury

Figure 1. Origins of cardiac fibroblasts during cardiac development and following acute ischemic injury

The cardiac fibroblast in the injured heart has diverse origins compared to the fibroblast in the developing heart. 


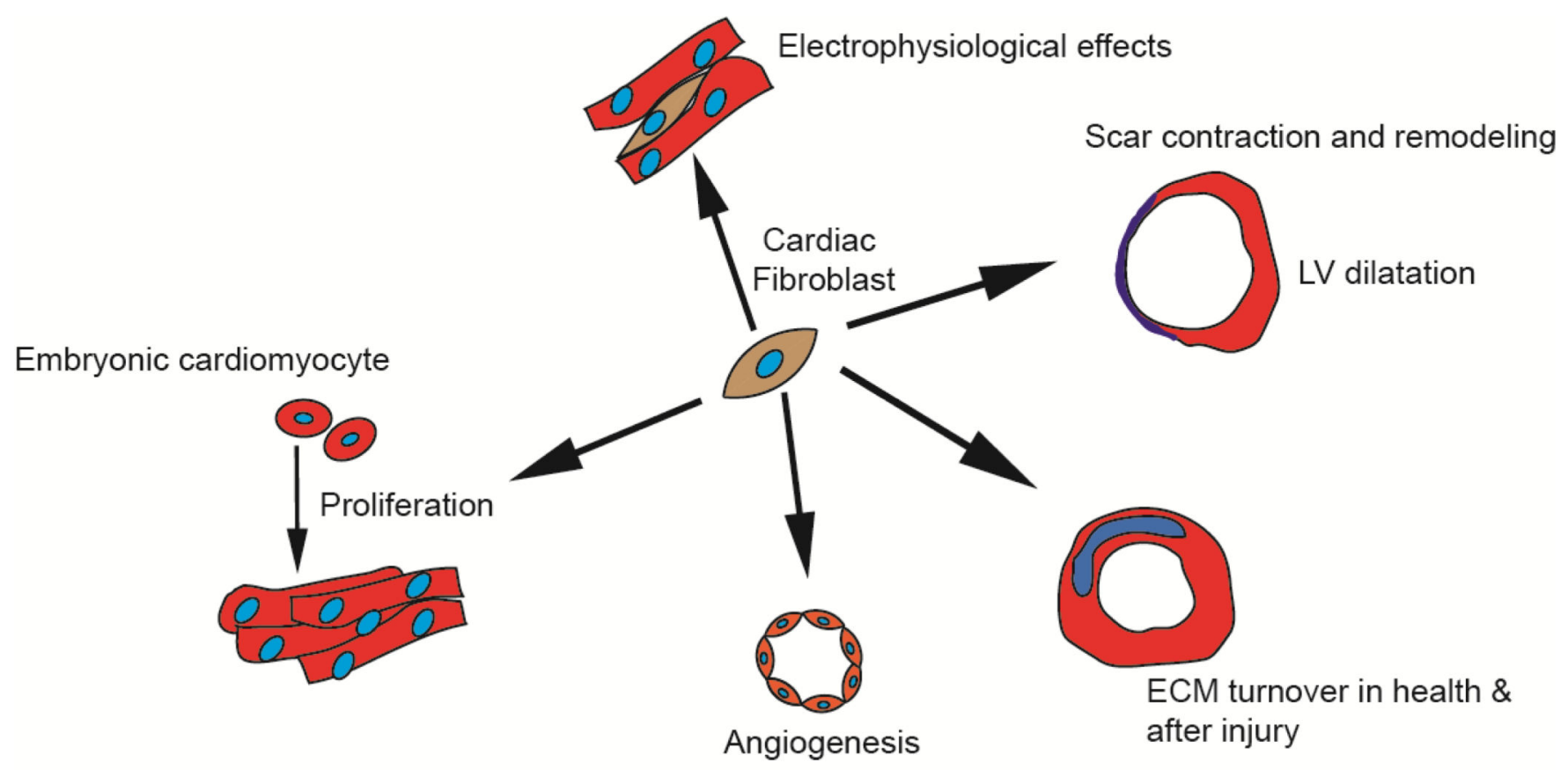

Figure 2. Major functions of the fibroblast during cardiac development and wound healing The fibroblast promotes proliferation of embryonic cardiomyocytes. It influences angiogenesis in the adult heart, regulates ECM turnover both in the adult uninjured heart and after acute injury. The fibroblast plays a pathophysiological role in scar contraction, adverse remodeling and ventricular dilatation and exerts electrophysiological effects. 

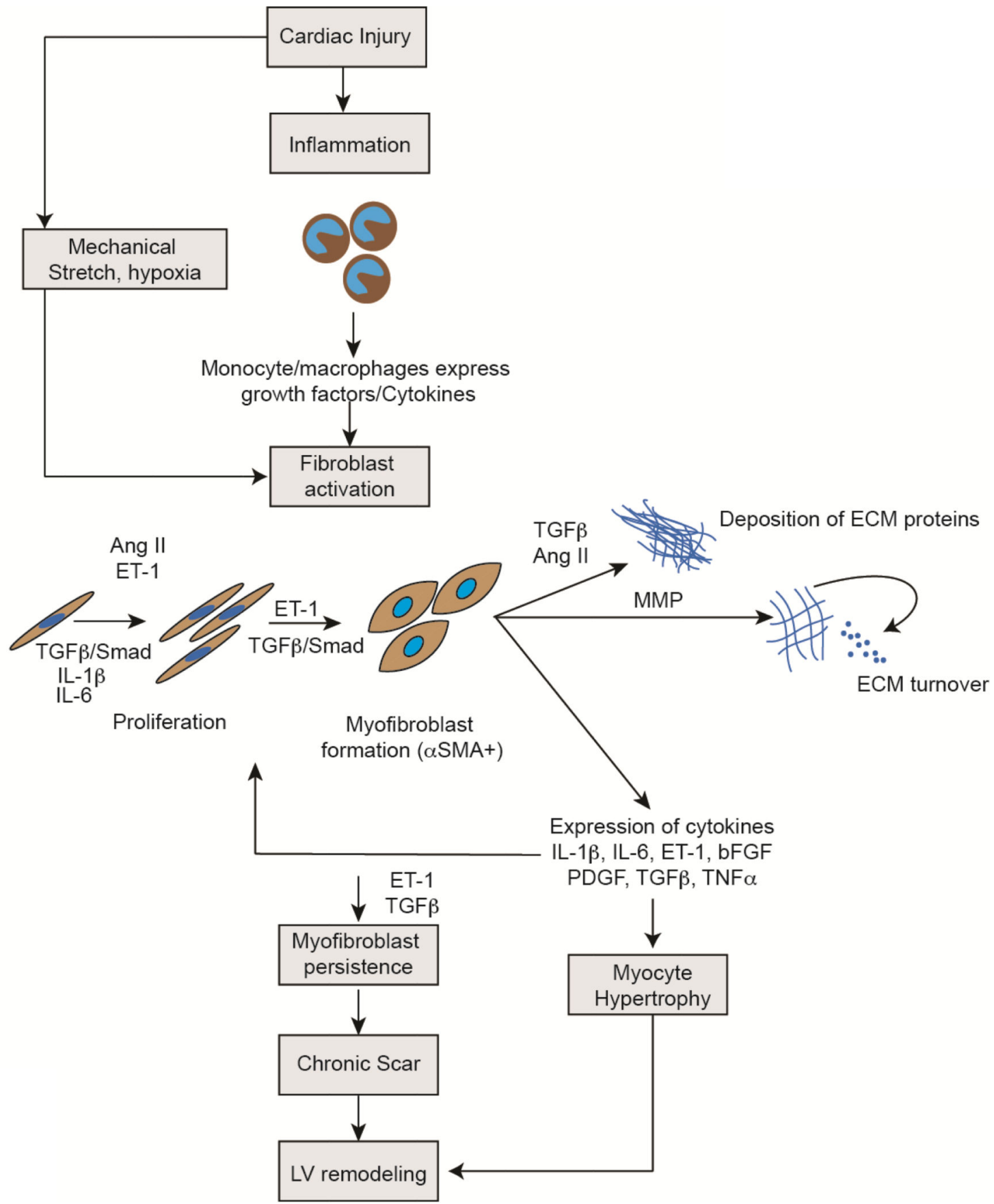

Figure 3. Signaling pathways regulating pathophysiological effects of cardiac fibroblasts after cardiac injury

Following cardiac injury, monocyte/macrophage infiltrate at the site of injury release growth factors and cytokines that activate cardiac fibroblasts. Mechanical stretch and hypoxia in addition are potent activators of fibroblasts. TGF $\beta$, ET-1, Ang II and other inflammatory cytokines such as IL-1 $\beta$ and IL-6 induce cardiac fibroblast proliferation, formation of myofibroblast, deposition of extracellular matrix and matrix turnover. The fibroblast itself expresses many of these pro-fibrotic cytokines that exert effects via autocrine/paracrine mechanisms. Cytokines expressed by cardiac fibroblasts also induce cardiomyocyte 
hypertrophy. Persistence of myofibroblasts in the injury region leads to continuing matrix turnover, formation of chronic scar and along with myocyte hypertrophy leads to adverse ventricular remodeling. (TGF $\beta$ : Transforming Growth Factor $\beta$, IL: Interleukin, ET-1:

Endothelin 1, Ang II: Angiotensin II, bFGF: Basic Fibroblast Growth Factor, PDGF: Platelet Derived Growth Factor, TNFa: Tumor Necrosis Factor a, ECM: Extracellular matrix) 


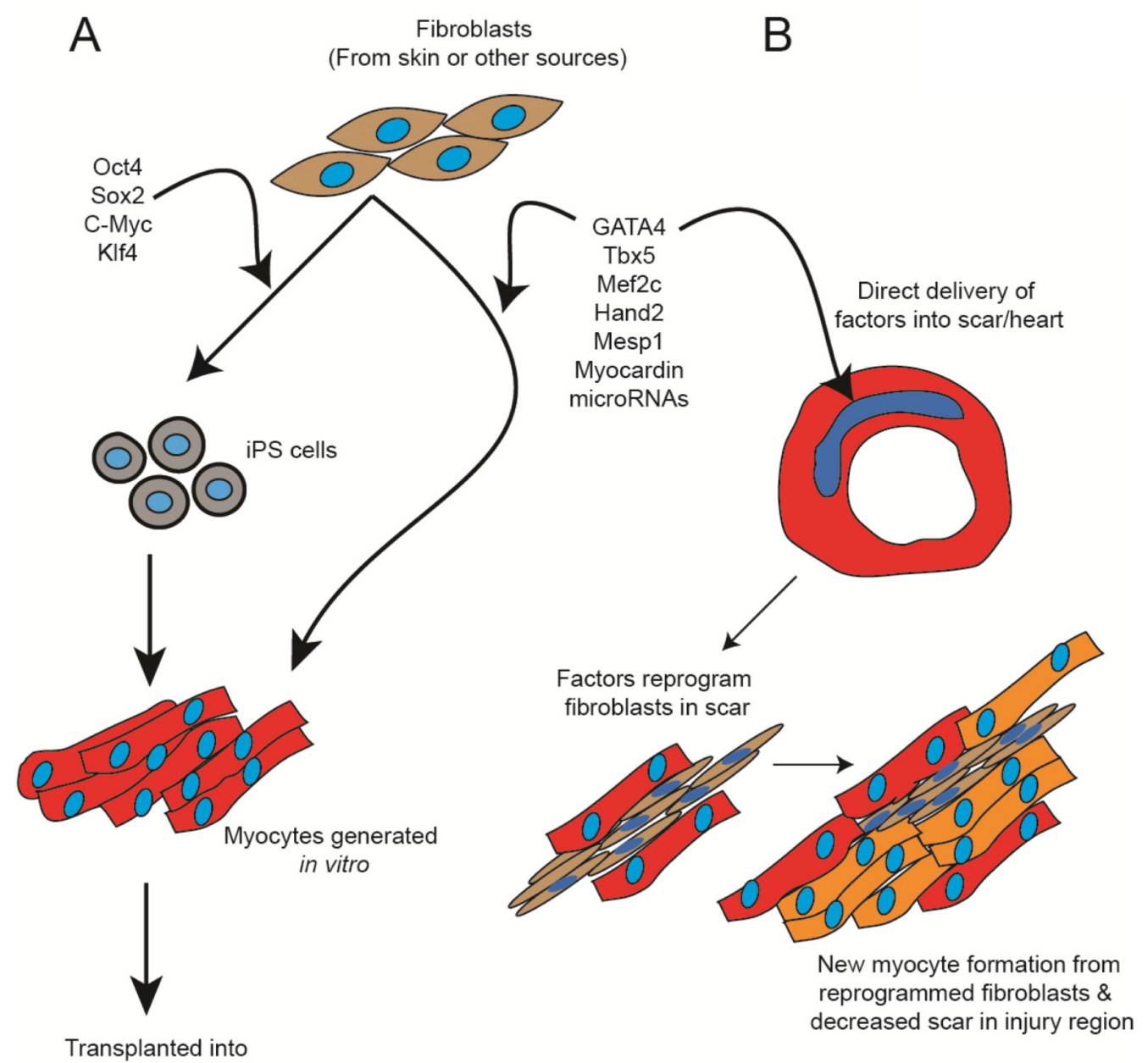
failing or infarcted hearts

Cardiac fibroblast in injured region

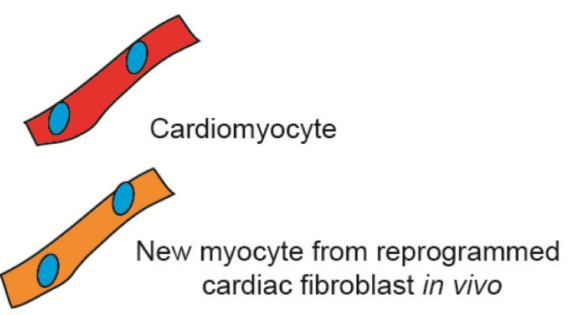

Figure 4. Targeting the fibroblast for cardiac regeneration

Fibroblasts can be reprogrammed into cardiomyocytes using cocktails of reprogramming factors. (A) In one approach, fibroblasts isolated from skin or other tissues of a ptient can be transduced with cocktails of transcription factors to yield induced pluripotent stem cells (iPS cells). Subsequently iPS cells generated from these fibroblasts can be differentiated in-vitro into cardiomyocytes that could be subsequently transplanted into failing or injured hearts. Alternatively combinations of factors can be used to directly reprogram the fibroblast to a cardiomyocyte in-vitro bypassing the iPS step and then generated cardiomyocytes would be 
transplanted in a similar manner. (B) In an alternative approach, combinations of factors can be directly delivered into the fibrotic region after cardiac injury. Cardiac fibroblasts in the injury region can directly reprogram into cardiomyocytes that potentially can integrate with existing cardiomyocytes to enhance cardiac function. By reprogramming fibroblasts in the injury region to form cardiomyocytes, this strategy would also decrease fibrosis and potentially ameliorate remodeling. 


\section{Table 1}

Changes in cardiac fibroblasts numbers from late development to adulthood in the murine heart. Adapted from [3].

\begin{tabular}{lc}
\hline Developmental Stage & Fraction of all heart cells \\
\hline E18.5 & $14 \%$ \\
Post natal Day 1 & $10 \%$ \\
Post natal Day 5 & $14 \%$ \\
Post natal Day 15 & $18 \%$ \\
Adult & $27 \%$ \\
\hline
\end{tabular}




\section{Table 2}

Contribution of fibroblasts to the cellular composition of the adult murine and rat heart. (Numbers expressed as a fraction of all heart cells). Adapted from [3].

\begin{tabular}{lcc}
\hline Cell type & Mouse & Rat \\
\hline Cardiac fibroblasts & $27 \%$ & $64 \%$ \\
Myocytes & $56 \%$ & $30 \%$ \\
$\begin{array}{l}\text { Non-myocyte/non cardiac } \\
\text { fibroblasts }\end{array}$ & $17 \%$ & $6 \%$ \\
\hline
\end{tabular}

